\title{
Structure-Activity Relationships of Hierarchical Three-Dimensional Electrodes with Photosystem II for Semiartificial Photosynthesis
}

\author{
Xin Fang, ${ }^{\dagger}$ Katarzyna P. Sokol, ${ }^{\dagger}$ Nina Heidary, ${ }^{\dagger}$ Tarek A. Kandiel, ${ }^{\dagger, \ddagger \subset}$ Jenny Z. Zhang, ${ }^{\dagger}$ \\ and Erwin Reisner*, ${ }^{*}$ \\ ${ }^{\dagger}$ Department of Chemistry, University of Cambridge, Cambridge CB2 1EW, United Kingdom \\ ${ }^{\ddagger}$ Department of Chemistry, Faculty of Science, Sohag University, Sohag 82524, Egypt
}

\section{Supporting Information}

\begin{abstract}
Semiartificial photosynthesis integrates photosynthetic enzymes with artificial electronics, which is an emerging approach to reroute the natural photoelectrogenetic pathways for sustainable fuel and chemical synthesis. However, the reduced catalytic activity of enzymes in bioelectrodes limits the overall performance and further applications in fuel production. Here, we show new insights into factors that affect the photoelectrogenesis in a model system consisting of photosystem II and three-dimensional indium tin oxide and graphene electrodes. Confocal fluorescence microscopy and in situ surfacesensitive infrared spectroscopy are employed to probe the enzyme distribution and penetration within electrode scaffolds of different structures, which is further correlated with protein film-photoelectrochemistry to establish relationships between the electrode architecture and enzyme activity. We find that the hierarchical structure of electrodes mainly influences the protein loading but not the enzyme activity. Photoactivity is more limited by light intensity and electronic communication at the biointerface. This study provides guidelines for maximizing the performance of semiartificial photosynthesis and also presents a set of methodologies to probe the photoactive biofilms in three-dimensional
\end{abstract} electrodes.

KEYWORDS: Photosystem II, inverse opal, indium tin oxide electrode, graphene electrode, semiartificial photosynthesis

$\mathrm{N}$ atural photosynthesis harvests sunlight to energize electrons and pump protons from water oxidation for carbon dioxide fixation, which is carried out by a series of enzymes that are orchestrated in thermodynamics and kinetics. ${ }^{1,2}$ Photosystem II (PSII) is the only enzyme known able to photocatalyze the energy-demanding water oxidation reaction at a high turnover frequency (TOF) of $\sim 100 \mathrm{~s}^{-1}$, extracting electrons from water and initiating the vectorial electron transfer in the thylakoid membrane (Figure S1a)., Photoelectrogenesis in PSII starts from the excitation of the reaction center chlorophylls (P680), followed by electron transfer from the excited $\mathrm{P} 680^{*}$ to the terminal acceptor plastoquinone $B\left(Q_{B}\right)$ via pheophytin and plastoquinone $A$ (Figure $\mathrm{S} 1 \mathrm{~b}){ }^{5}$ In nature, the fully reduced $\mathrm{Q}_{\mathrm{B}}\left(\mathrm{Q}_{\mathrm{B}} \mathrm{H}_{2}\right)$ will dissociate from the reaction center complex and donate the electrons to photosystem I (PSI) via a cytochrome $b_{6} f$ complex. ${ }^{6}$ The electron transfer pathway from PSII to the cytochrome can be intercepted by exogenous acceptors such as molecular mediators and synthetic electrodes, ${ }^{5,7,8}$ which enables unique opportunities to redirect the photosynthetic electron flux for chemical synthesis and fuel production (Figure S1c).

Semiartificial photosynthesis combines strengths of both synthetic materials and biocatalysts to produce value-added chemicals with high selectivity and efficiency, which cannot be achieved by synthetic biology or artificial photosynthesis alone. $^{9-11}$ Photosynthetic enzymes have been wired into many synthetic electrodes via self-assembled monolayers, metal oxide scaffolds, and redox polymer matrices, but their responsive photocurrent was limited by the low protein loading. ${ }^{12-18}$ To overcome this limitation, hierarchical threedimensional (3D) electrodes with high surface area were produced to enhance protein loading and facilitate electron exchange at the protein-electrode interface (biointerface). ${ }^{19,20}$ For example, inverse opal-indium tin oxide (IO-ITO) electrodes allow proteins to penetrate through their interconnected macropores and have mesoporous skeletons with high surface area for protein binding and electronic communication (Figure 1a), ${ }^{21-24}$ thereby increasing the mediated photocurrent up to $1 \mathrm{~mA} \mathrm{~cm}{ }^{-2} \cdot{ }^{25,26}$ An attractive alternative to ITO are graphene materials as they can provide conductive and biocompatible surfaces for biocatalysts at low cost. $^{27,28}$ In addition, the surface chemistry of graphene materials can be readily modified via physical/chemical approaches, ${ }^{29,30}$ which creates variable platforms to investigate

Received: December 10, 2018

Revised: January 15, 2019

Published: January 28, 2019 
a

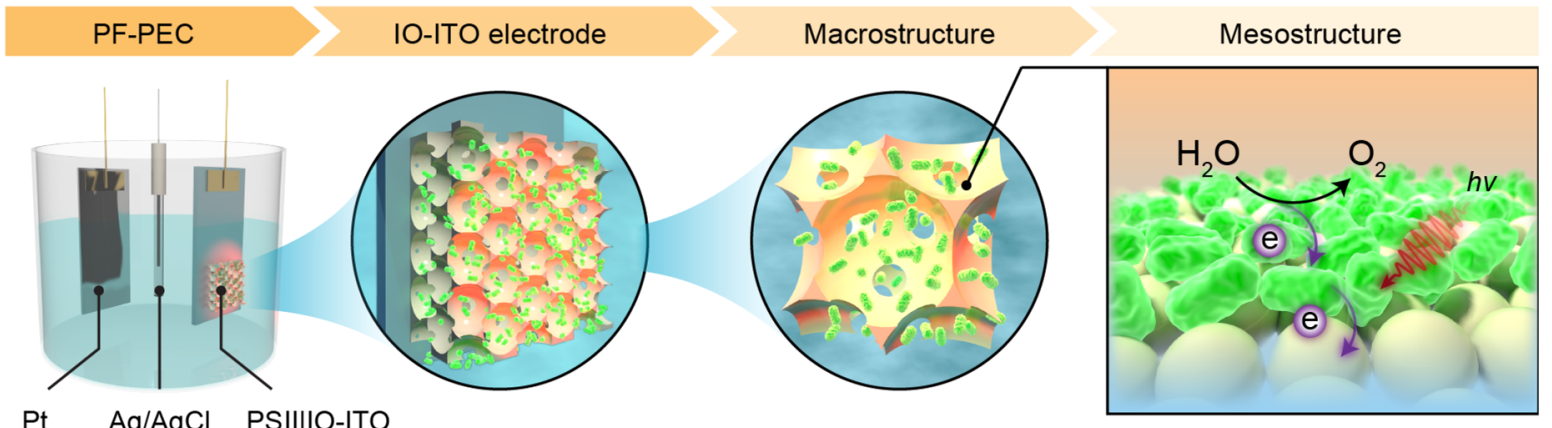

Pt $\quad \mathrm{Ag} / \mathrm{AgCl} \quad \mathrm{PSII|OO}-\mathrm{TTO}$

QID PS II ITO nanoparticle

b

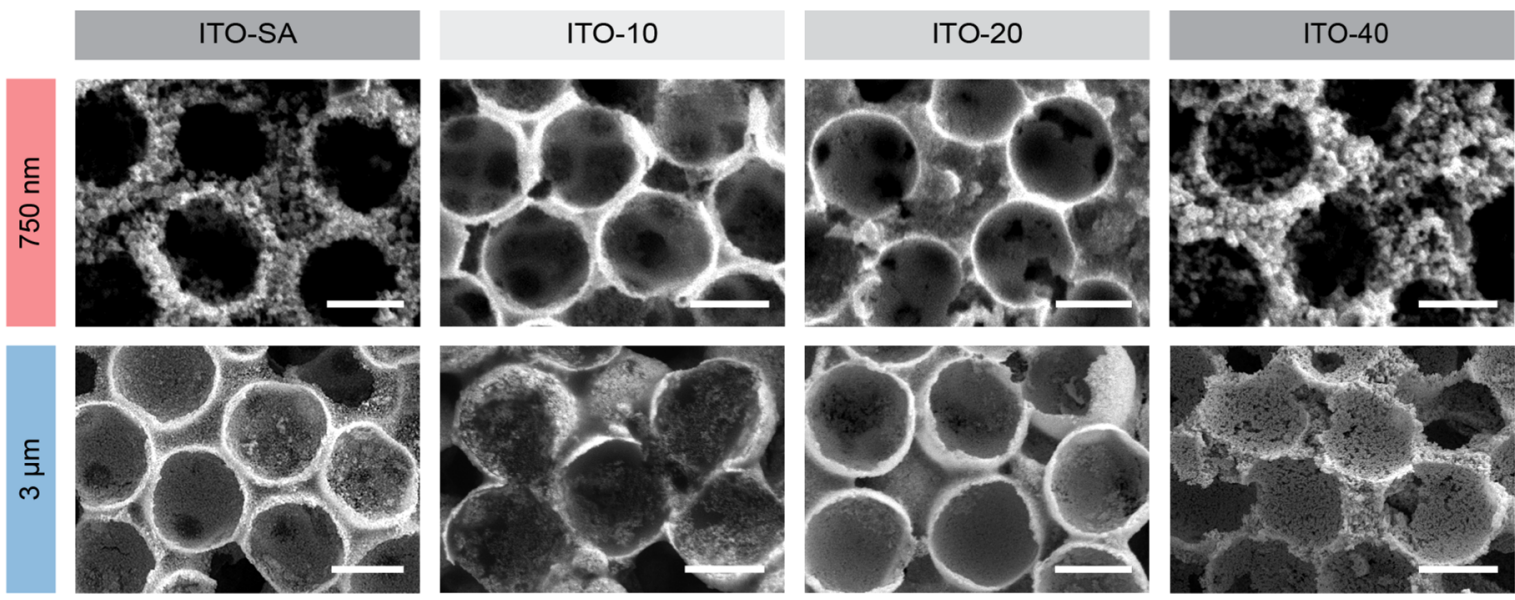

Figure 1. Integration of PSII into IO-ITO electrodes for semiartificial photosynthesis. (a) Schematic representation of hierarchical structures of the IO-ITO electrodes. The PSII loaded IO-ITO electrode was used as the photoanode for PF-PEC. Platinum and $\mathrm{Ag} / \mathrm{AgCl}$ were used as the counter and reference electrode, respectively. The IO-ITO electrode features interconnected macropores that enable protein penetration and integration. PSII can immobilize in the mesoporous scaffold that was composed of ITO nanoparticles. (b) SEM images of $750 \mathrm{~nm}$ IO-ITO electrodes and $3 \mu \mathrm{m}$ IO-ITO electrodes made with different ITO nanoparticles. Scale bars: $500 \mathrm{~nm}$ (top); $2 \mu \mathrm{m}$ (bottom).

the interaction at biointerfaces. ${ }^{31,32}$ Planar graphene electrodes have been used to interface with isolated photoactive enzymes and intact photosynthetic apparatus, which usually produced submicroampere photocurrent that has no practical significance. ${ }^{33-38}$ A variety of 3D graphene structures have been applied for photovoltaics and electrocatalysis, ${ }^{39-41}$ but they have not yet been used to host photoactive enzymes for semiartificial photosynthesis.

A major challenge facing semiartificial photosynthesis is that enzymes integrated in electrodes often exhibit reduced activity when stripped from their in vivo environment and that only a small fraction of enzymes at the biointerface are in an electroactive orientation (Figure S1d). ${ }^{5}$ Addressing these challenges requires an in-depth interrogation of bioelectrodes to pinpoint factors governing the photoelectrogenesis at the biointerface. Nevertheless, such investigations are lacking due to difficulties in characterizing the nanoscale proteins in complex 3D structures, which makes the protein-electrode interaction and its correlation with photoelectrochemistry largely unclear, and further challenges efforts to enhance the photocatalytic performance of bioelectrodes.

Here, we present a systematic study of PSII-integrated 3D electrodes to outline the structure-activity relationship underlying photoelectrogenesis therein, through a new approach combining material synthesis, microscopy, spectroscopy, and photoelectrochemistry. We prepared IO-ITO electrodes and IO-graphene electrodes with varied macro- and mesostructures to integrate with PSII. We employed confocal fluorescence microscopy and in situ infrared spectroscopy to visualize the protein distribution and monitor their penetration into the electrode scaffolds, respectively, and finally correlated with the enzyme activity that was quantified by protein-film photoelectrochemistry (PF-PEC). We find that the $3 \mathrm{D}$ hierarchical electrodes with smaller macropores and mesopores larger than the protein size enable higher loading capacity and better enzyme retention, whereas the individual enzyme activity is more sensitive to the light intensity and electronic communication at the biointerface, rather than the electrode morphology. Our results reveal the relationship between the electrode structure and enzyme activity and provide useful guidelines for the design and optimization of photoactive bioelectrodes.

We prepared IO-ITO electrodes with different macro- and mesostructures using a co-assembly method with polystyrene (PS) beads and ITO nanoparticles, followed by annealing (Figure $1 \mathrm{~b}) .{ }^{25,26}$ We employed $750 \mathrm{~nm}$ and $3 \mu \mathrm{m}$ PS beads to create different macropores: larger PS beads will produce larger macropores and interconnecting channels after heat treatment for protein penetration but reduce the effective surface area for protein binding. To vary the mesostructure, we used polydispersed ITO nanoparticles (Sigma-Aldrich, SA) and synthesized monodispersed ITO nanoparticles with average sizes of approximately $10 \mathrm{~nm}$ (ITO-10), $20 \mathrm{~nm}$ (ITO-20) and $40 \mathrm{~nm}$ (ITO-40) (Figures S2 and S3 and Supporting 
Information for experimental details). ${ }^{42}$ The ITO nanoparticles will assemble into mesoporous and hydrophilic surfaces that will directly interface with proteins (Figure S4). All the electrodes had a geometrical area of $0.25 \mathrm{~cm}^{2}$. The film thickness has been optimized as $20 \mu \mathrm{m}$ to balance the protein loading and light absorption (Figures S5 and S6). ${ }^{25,26}$

The IO-graphene electrodes were prepared by coassembling graphene oxide (GO) microsheets and PS beads (Figure $S 7 a-c) .{ }^{43}$ PS beads were first mixed with a GO solution and dropcast on an ITO substrate. The GO-PS film was then annealed at $500{ }^{\circ} \mathrm{C}$ to remove the PS beads and reduce GO into graphene (reduced GO) (Figure S7d-g). ${ }^{44-47}$ The hydrophilicity of graphene can be further improved by ozone treatment (Figure S7g). ${ }^{48}$ The graphene electrode scaffold is composed of planar graphene sheets, which provides a large surface area but minor porosity and roughness compared to IO-ITO scaffolds (Figure S7h). We prepared IO-graphene electrodes with different morphologies by varying the size of PS beads $(750 \mathrm{~nm}$ and $3 \mu \mathrm{m})$ and the concentration of GO solutions ( Gr I, $4 \mathrm{mg} \mathrm{mL}^{-1}$ and Gr II, $10 \mathrm{mg} \mathrm{mL}^{-1}$ ) (Figure S8). In IO-graphene electrodes, the PS beads dictate the macroporosity, whereas the concentration of the GO solution mainly affects the surface area and pathways for enzyme penetration. More graphene sheets provide higher surface area for protein binding but may also block channels for protein integration and attenuate the light intensity. The major morphological difference with ITO counterparts is that macropores in IO-graphene electrodes were not interconnected. Proteins therefore can only penetrate into the electrodes via channels created by thermal decomposition of PS.

The electrochemical properties of IO-ITO and IOgraphene electrodes were studied by cyclic voltammetry (CV). CV scans of both IO electrodes showed a typical electrical double layer capacitive behavior and electrochemical stability within the potential window of $0-0.5 \mathrm{~V}$ (vs SHE) at $\mathrm{pH} 6.5$ (Figure S9a-c). As the capacitance of the electrical double layer capacitor scales proportionally with the electrochemically active surface area, ${ }^{49}$ we used the specific capacitance as a measure of the surface area accessible to electrolyte solution. ${ }^{21}$ The specific capacitance of IO-ITO electrodes decreased with increasing particle size as the smaller nanoparticles create a higher effective surface area (Figure 2a). The $750 \mathrm{~nm}$ IO-graphene electrodes displayed a higher capacitance than $3 \mu \mathrm{m}$ electrodes. Increasing graphene will introduce more structural blockage for electrolyte penetration in $750 \mathrm{~nm}$ electrodes, thus reducing the capacitance, whereas it will provide more surface area instead of blocking the macropores in $3 \mu \mathrm{m}$ electrodes (Figure S9d).

The light transmission of electrodes was measured by ultraviolet-visible (UV-vis) spectroscopy (Figure S10a-c). All the IO electrodes showed similar transmittance $(<4 \%)$ regardless of materials, macro- and mesostructures (Figure S10d). Because of its wide bandgap $(>4 \mathrm{eV})$, ITO has minimum light absorbance in the visible-light spectrum and therefore has been widely used for transparent electrodes. ${ }^{50,51}$ Thus, we suspect that most of the light can penetrate within the $20 \mu \mathrm{m}$ thick IO-ITO scaffold aided by strong internal scattering and the incident light is largely accessible to photoactive proteins embedded in the IO-ITO scaffold. ${ }^{52,53}$ However, given that reduced GO is a strong absorber of visible light, $^{54}$ the light intensity will be attenuated when light
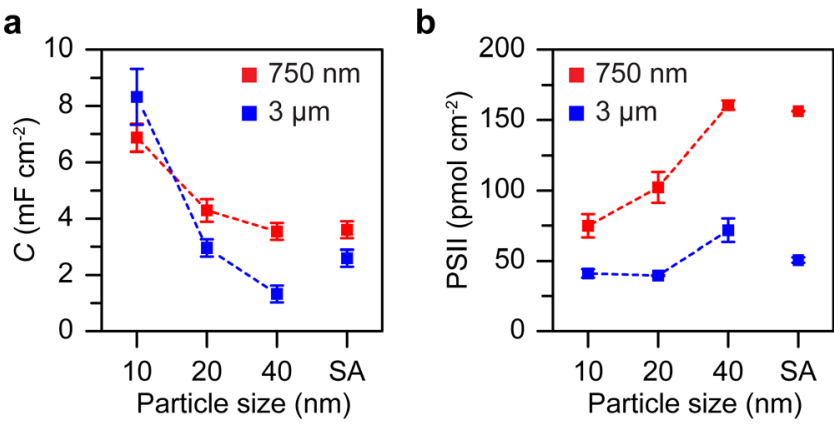

C

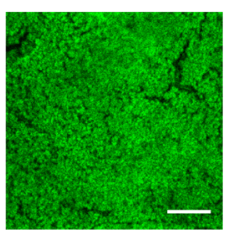

d
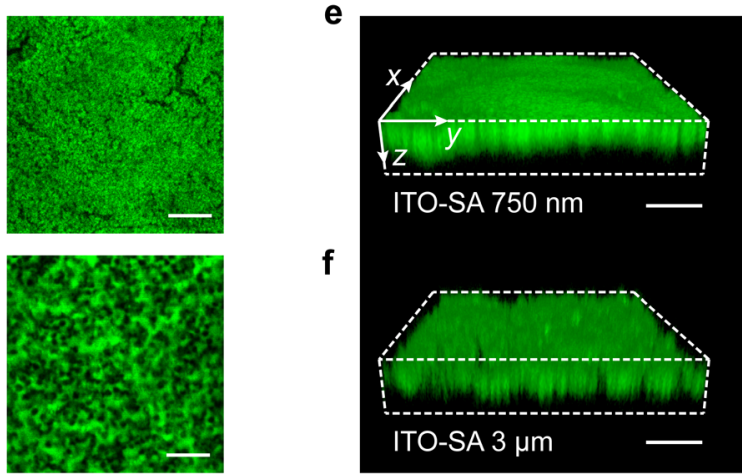

Figure 2. PSII integration and distribution within IO-ITO electrodes. (a) Specific capacitance of IO-ITO electrodes obtained from CV scans (mean \pm s.d., $n=3$ ). (b) PSII loadings on IO-ITO electrodes obtained from UV-vis analysis (mean \pm s.d., $n=3)$. (c,d) CLSM images of the PSII in ITO-SA $750 \mathrm{~nm}$ (c) and ITO-SA $3 \mu \mathrm{m}$ (d) electrodes. $(\mathrm{e}, \mathrm{f})$ The $3 \mathrm{D}$ visualization of the PSII distribution within ITO-SA $750 \mathrm{~nm}$ (e) and ITO-SA $3 \mu \mathrm{m}$ (f) electrodes.The 3D view was reconstructed from $\mathrm{Z}$-stacking images that were acquired by scanning $20 \mu \mathrm{m}$ downward from the electrode surface. Excitation: $\lambda_{\mathrm{ex}}$ $=633 \mathrm{~nm}$. Emission: $\lambda_{\mathrm{em}}=650-750 \mathrm{~nm}$. Scale bars in (c-f): $20 \mu \mathrm{m}$.

transmits through the IO-graphene electrode, undermining the photoexcitation of enzymes therein.

PSII isolated from the cyanobacterium Thermosynechococcus elongatus was loaded on the electrodes by dropcasting (Figure S11), followed by rinsing with the electrolyte solution to remove the weakly bound PSII. PSII immobilized within the electrodes was quantified by UV-vis analysis analysis (see Supporting Information for details). ${ }^{26}$ More PSII was bound on $750 \mathrm{~nm}$ than $3 \mu \mathrm{m}$ IO-ITO electrodes (Figure $2 \mathrm{~b}$ ). ITO40 and ITO-SA electrodes with the same macropore size achieved higher PSII loading, which is contrary to their smallest surface area and further suggests the electrode's surface area cannot be fully translated into the capacity for binding proteins. The fact that mesopores larger than the protein size $(\sim 20 \mathrm{~nm} \times 10 \mathrm{~nm} \times 10 \mathrm{~nm}$ for a cyanobacterial PSII dimer $)^{4}$ enabled better immobilization implies proteins are likely entrapped within the cavities formed by ITO nanoparticles. Despite comparable capacitance, IO-graphene electrodes exhibited much lower PSII loading than IO-ITO electrodes (Figure S12), which is likely due to weaker interaction and lack of effective pathways for protein penetration. At the center of electrode design for bioelectronics is creating large conductive surfaces to interface with redoxactive proteins. ${ }^{20}$ However, this well-known principle should be complemented by considering the protein-electrode interaction to ensure the increased surface is accessible to the proteins. 
a

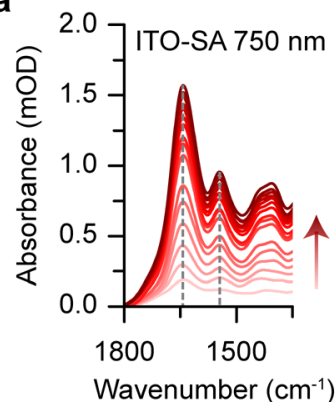

b

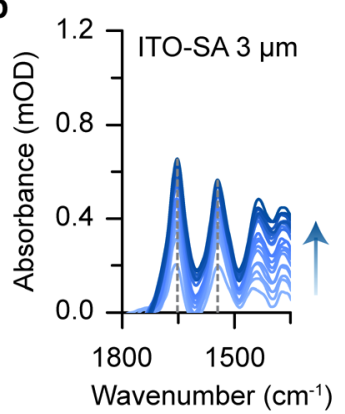

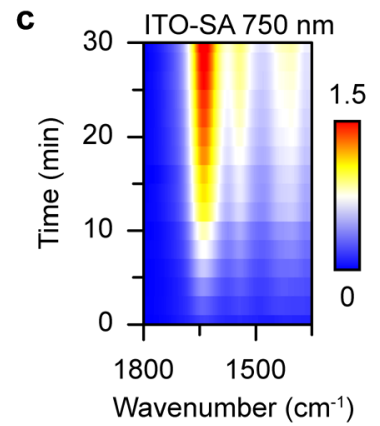

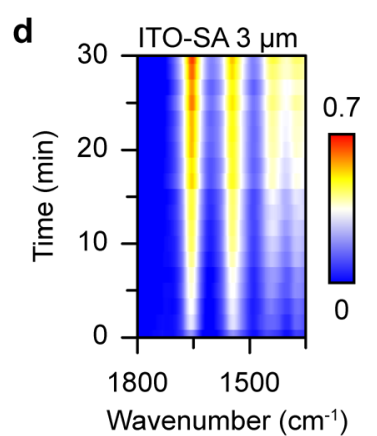

e

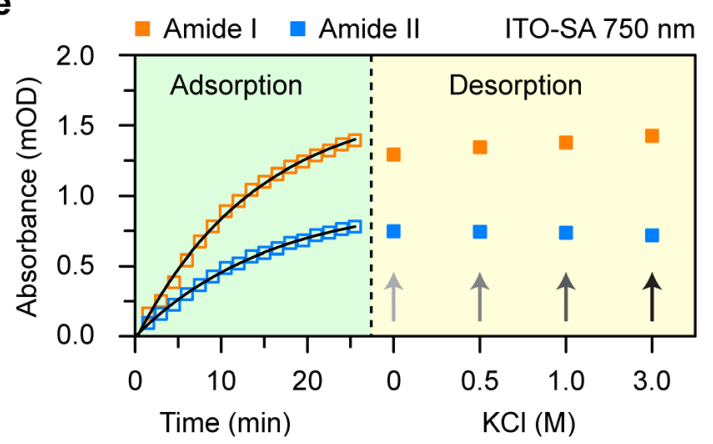

$\mathbf{f}$

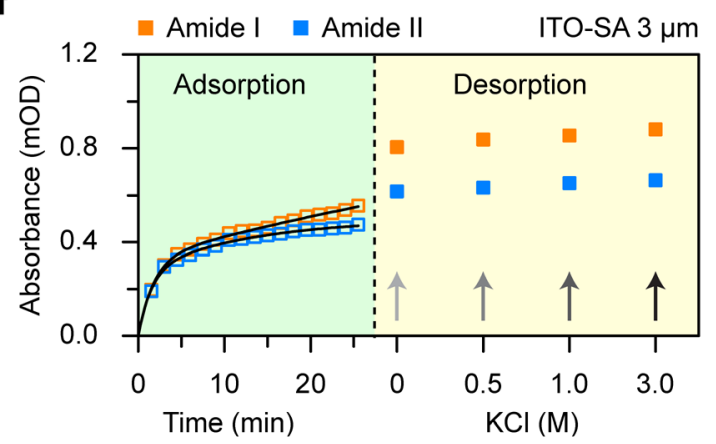

Figure 3. ATR-IR spectroscopy of PSII-loaded IO-ITO scaffolds. (a,b) ATR-IR spectra of PSII adsorption at the bottom of ITO-SA $750 \mathrm{~nm}$ (a) and ITO-SA $3 \mu \mathrm{m}$ (b) scaffolds. (c,d) The 2D visualization of the position and intensity of amide bands during the PSII adsorption in ITO-SA 750 $\mathrm{nm}(\mathrm{c})$ and ITO-SA $3 \mu \mathrm{m}$ (d) scaffolds. The color bars indicate the IR absorbance (mOD). (e,f) Adsorption kinetics and desorption experiments of PSII loaded in ITO-SA $750 \mathrm{~nm}$ (e) and ITO-SA $3 \mu \mathrm{m}$ (f) scaffolds. The biexponential fitting is shown as black lines in (e,f).

Despite numerous bioelectrodes developed for semiartificial photosynthesis, PSII integration and distribution within electrodes has not been studied, which makes it difficult to evaluate the contribution of electrode structures. ${ }^{5}$ Here, we employed confocal laser scanning microscopy (CLSM) to visualize the spatial distribution of PSII within the $3 \mathrm{D}$ electrode scaffolds by its strongly fluorescent chlorophyll $a$ (Chl a) molecules (see Figures S13-S15 for control experiments). The morphology of PSII films reflects the macroscale structural features of electrodes such as macroporosity and cracks (Figure S16a). PSII uniformly distributed in $750 \mathrm{~nm} \mathrm{IO-ITO}$ electrodes whereas it formed aggregates in $3 \mu \mathrm{m}$ IO-ITO electrodes (Figure $2 \mathrm{c}, \mathrm{d}$ ). In both cases, PSII can penetrate throughout the entire IO-ITO scaffold via channels interconnecting macropores (Figures 2e,f and S16b). The depth profile of fluorescence indicates that most PSII populated in the middle range of the electrode scaffold (Figure S17). Although the light intensity will decay along the electrode depth, the light scattering within the electrode will likely enable most PSII to access irradiation. In IO-graphene electrodes, CLSM images show that the enzymes could penetrate through the IO-graphene electrodes except Gr II$750 \mathrm{~nm}$, where most PSII accumulated near to the surface due to excess graphene blocking pathways for protein penetration (Figure S18).

We further investigated the protein-electrode interaction by probing the dynamic process of protein adsorption and desorption within the $3 \mathrm{D}$ scaffold. This was possible by employing in situ attenuated total reflection-infrared (ATR-IR) spectroscopy to track the PSII penetration within IO-ITO scaffolds. ATR-IR spectroscopy features its surface-sensitivity to molecular vibration and can indicate protein unfolding or denaturation through changes in its spectral bands. ${ }^{55,56}$ The ATR-IR setup consisted of a $20 \mu$ m-thick IO-ITO scaffold deposited on a silicon prism (Figure S19a). As the evanescent IR wave will penetrate $\sim 0.5 \mu \mathrm{m}$ from the internal surface of the silicon prism, ${ }^{56}$ the monitored spectral features of protein amide bands can only stem from PSII at the bottom layer of the IO-ITO scaffold. Hence, the dynamic adsorption process of PSII can be monitored by its characteristic amide I and amide II bands centered at 1656 and $1546 \mathrm{~cm}^{-1}$, respectively (Figure S19b). ${ }^{57}$

When PSII was dropcast on the IO-ITO scaffold, the growing intensities of both amide I and amide II bands indicated an increased amount of PSII reaching the bottom of the IO-ITO structure, confirming the penetration of PSII through the entire $20 \mu \mathrm{m}$-thick film (Figure 3a,b). While positions of amide I and amide II bands remained unchanged during the PSII adsorption in both $750 \mathrm{~nm}$ and $3 \mu \mathrm{m} \mathrm{IO-ITO}$ scaffolds (Figure 3c,d), their intensity followed a biexponential increase consisting of a fast and a slow kinetic process (Figure $3 \mathrm{e}, \mathrm{f})$. The first exponential growth was completed after $15 \mathrm{~min}$ for $750 \mathrm{~nm}$ and $1.8 \mathrm{~min}$ for $3 \mu \mathrm{m}$ electrodes, which shows larger macropores favor fast protein penetration within the 3D scaffold and further suggests smaller macropores enable more mesoporous skeletons available for protein adsorption.

The nature of protein-electrode interaction was examined by a desorption experiment: the PSII-loaded IO-ITO scaffolds were washed with the PSII stock buffer solution (10\% glycerol,

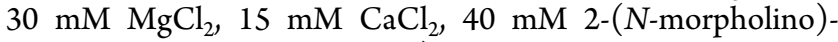
ethanesulfonic acid, $\mathrm{pH}$ 6.5) and buffer solutions with increasing $\mathrm{KCl}$ concentrations $(0.5 \mathrm{M}, 1.0 \mathrm{M}, 3.0 \mathrm{M})$. In the $750 \mathrm{~nm}$ IO-ITO scaffold, the desorption process caused only minor changes in the amide bands intensities (Figure $3 \mathrm{e}$ ), suggesting PSII was well-retained within the scaffold. In contrast, the amide bands increased steadily with $\mathrm{KCl}$ concentrations in the $3 \mu \mathrm{m}$ IO-ITO scaffold (Figure 3f), indicating that an increased amount of PSII was desorbed from 
the scaffold by high ionic strength solutions and penetrated deeper into the IO scaffold thereafter. The difference in protein desorption can be attributed to the macroporosity, where desorbed proteins are more likely to be recaptured by the $750 \mathrm{~nm}$ IO-ITO scaffold but diffuse to the bottom in the $3 \mu \mathrm{m}$ IO-ITO scaffold. The protein desorption induced by the high ionic strength solutions points to a dominating electrostatic interaction between PSII and the IO-ITO scaffold, ${ }^{58}$ which can be further verified by the desorption experiment on a planar ITO surface (Figure S20). The positive charge of ITO nanoparticles ( $\zeta$-potential: $+32 \mathrm{mV}$ at $\mathrm{pH} 6.5$ ) enables PSII to interact with the IO-ITO scaffold via its negatively charged surfaces (Figure S21). ${ }^{59-61}$

The photoactivity of PSII-loaded electrodes was quantified by PF-PEC. Direct electron transfer (DET) photocurrent of IO-ITO electrodes correlated broadly with the PSII loading, except for ITO-40 $750 \mathrm{~nm}$ that underperformed in DET compared with the ITO-SA $750 \mathrm{~nm}$ electrode (Figure 4a, S22 and Table S1). This may be due to thick PSII films that were inadequately wired by the conductive scaffold in ITO-40 750 $\mathrm{nm}$ and monodispersed ITO-40 nanoparticles that formed less contact sites with PSII compared with polydispersed ITO-SA nanoparticles. This problem was mitigated by introducing a diffusional redox mediator (2,5-dichloro-1,4-benzoquinone, DCBQ) that can relay electrons from proteins to the electrode, regardless of aggregates and orientation. Both ITO-40 and ITO-SA $750 \mathrm{~nm}$ electrodes showed a comparable mediated electron transfer (MET) photocurrent (Figure 4a). The MET photocurrent of $750 \mathrm{~nm}$ IO-ITO electrodes increased proportionally with the PSII loading, whereas that of $3 \mu \mathrm{m}$ IO-ITO electrodes showed a major deviation from the PSII loadings, which may result from different mediator transport within protein films in different electrodes (Figure 4a). After PF-PEC measurements, less than $1 \%$ of PSII was released from the $750 \mathrm{~nm}$ IO-ITO electrode, whereas $22 \%$ were desorbed into the electrolyte solution from the $3 \mu \mathrm{m}$ IO-ITO electrode (Figure S23), which is consistent with the results from ATR-IR spectroscopy that the $750 \mathrm{~nm}$ IO-ITO scaffold enabled better retention of PSII. Long-term chronoamperometry shows that the half-life of protein films inside the $750 \mathrm{~nm} \mathrm{IO-ITO}$ electrode was $\sim 4 \mathrm{~min}$, significantly longer than that on a flat ITO electrode $(<1 \mathrm{~min})$, which manifests that the hierarchical structure is essential to secure the PSII within the electrode (Figure S24).

The TOF is calculated based on the photocurrent density and protein loading of the electrode (see Supporting Information for details), which represents the average photoactivity of PSII integrated in the electrodes (Figure $4 \mathrm{~b}$ and Table S1). Despite large differences in photocurrent, 750 $\mathrm{nm}$ IO-ITO electrodes showed a similar $\mathrm{TOF}_{\mathrm{DET}}$ of $0.07 \pm$ $0.02 \mathrm{~s}^{-1}$. The highest $\mathrm{TOF}_{\mathrm{DET}}$ was achieved on the ITO-SA $750 \mathrm{~nm}$ electrode $\left(0.10 \pm 0.01 \mathrm{~s}^{-1}\right)$ (Figure $\left.4 \mathrm{~b}\right)$. As the MET current largely varied with the PSII loading for $750 \mathrm{~nm}$ IOelectrodes, TOF $\mathrm{MET}_{\mathrm{M}}$ of $750 \mathrm{~nm}$ electrodes remained close to $2.8 \pm 0.5 \mathrm{~s}^{-1}$, which suggests the individual activity of PSII was less affected by the mesostructure of electrodes. Likewise, $3 \mu \mathrm{m}$ IO-ITO electrodes showed a TOF $_{\mathrm{DET}}$ of approximately 0.07 $\pm 0.01 \mathrm{~s}^{-1}$ (Figure 4b). The comparable TOF ${ }_{\mathrm{DET}}$ for $750 \mathrm{~nm}$ and $3 \mu \mathrm{m}$ IO-ITO electrodes despite their significant differences in photocurrent and PSII loadings suggests that the enzymatic activity is not dominated by the electrode morphology. When enzymes are integrated into electrodes, their TOFs are typically much lower than the average activity a

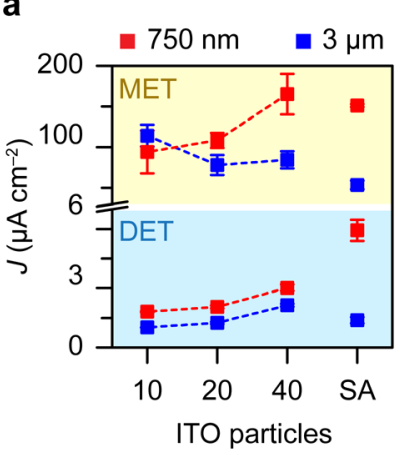

b

C

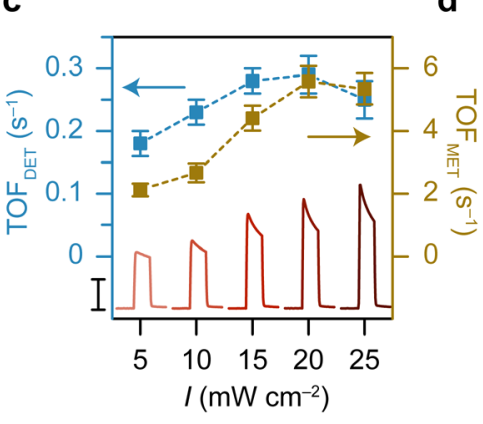

d

e

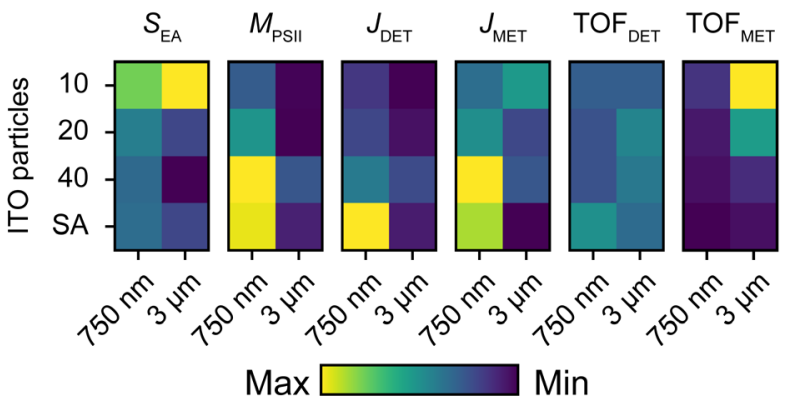

Figure 4. PF-PEC performance of PSII-loaded electrodes. (a,b) Photocurrent (a) and turnover frequencies (TOFs) (b) of PSIIloaded IO-ITO electrodes (mean \pm s.d., $n=3$ ). (c) TOF dependence on light intensity for the ITO-SA $750 \mathrm{~nm}$ electrode (insert: representative DET photocurrent traces, scale bar: $5 \mu \mathrm{A}$ $\mathrm{cm}^{-2}$ ). (d) Itemized comparison between IO-graphene and IO-ITO electrodes in electrochemically active surface area $\left(S_{\mathrm{EA}}\right.$, represented by specific capacitance), PSII loading $\left(M_{\mathrm{PSII}}\right)$, photocurrent, and TOFs of DET and MET. (e) Comparison of different IO-ITO electrodes in surface area, PSII loading, and photoelectrochemistry. The performance in each item is indicated by the color bar. Conditions for $(\mathrm{a}-\mathrm{c}): M_{\mathrm{PSII}}=157 \pm 7 \mathrm{pmol} \mathrm{cm}{ }^{-2}, \lambda=685 \mathrm{~nm}, I=10$ $\mathrm{mW} \mathrm{cm}{ }^{-2}$ (varied in (c)), $E=0.5 \mathrm{~V}$ (vs SHE), DCBQ ( $1 \mathrm{mM}$, for MET), $25{ }^{\circ} \mathrm{C}$.

of purified PSII used in this study (TOF: 20-30 s${ }^{-1}$ ) (Table S2), which indicates that most enzymes were not performing at their optimal rate. One limitation is the light intensity reaching PSII in electrode scaffolds. Both $\mathrm{TOF}_{\mathrm{DET}}$ and $\mathrm{TOF}_{\mathrm{MET}}$ increased with irradiation intensity up to $20 \mathrm{~mW} \mathrm{~cm}^{-2}$ and decreased with electrode thickness (Figures 4c and S25). For example, despite having higher PSII loading, the $80 \mu \mathrm{m}$ thick IO-ITO electrode had similar DET photocurrent with $40 \mu \mathrm{m}$ thick electrode, indicating inefficient electronic communication within the thick electrode scaffold, which was improved with diffusional mediators (Figure S25). Further possible limitations may reside in the insufficient wiring of proteins by the electrode scaffold, due to protein aggregation and random 
orientations. The adverse influence of protein orientation can be eliminated by modifying the surface chemistry of ITO to assist the electroactive orientation ${ }^{62}$ and by optimizing the surface mesoporosity of the electrode scaffold to multiply the contact sites to the enzyme. We also find that $\mathrm{TOF}_{\mathrm{MET}}$ would be affected by the mediator concentration, which may be due to the exogenous mediators quenching the excited antenna chlorophyll molecules (Figure S26). ${ }^{63,64}$

Compared with their ITO counterparts, PSII in graphene electrodes exhibited less photoactivity (Figure S27 and Table S3), which is likely due to the strong absorption of graphene sheets attenuating the light intensity reaching PSII. Moreover, graphene electrodes had less protein binding capacity, which can be attributed to their macrostructures that do not have sufficient interconnected channels for protein penetration and their mesostructures that lack topographical roughness to physically bind protein films. In addition, hydrophilic interaction has been previously suggested between PSI and GO. ${ }^{36}$ We thereby speculate PSII might preferably interact with the thermally reduced graphene through a similar manner (Figure S28), which is weaker than the electrostatic interaction taking place in IO-ITO electrodes.

In this work, we conducted a systematic study on PSIIintegrated 3D electrodes to reveal structure-activity relationships underlying photoelectrogenesis in photoactive bioelectrodes. (1) The protein integration in an electrode scaffold will be determined both by material and morphology. IO-ITO electrodes with small macropores and large mesoporosity tend to bind most proteins by physical/electrostatic interactions. (2) DET photocurrent arising from electronic communication between electroactive proteins and electrode surfaces correlates with the protein loading in the electrode. The photoactivity of PSII is not sensitive to the electrode morphology but will be governed by the light intensity and electronic communication at the biointerface. (3) MET photocurrent is convoluted by the interplay of protein loading and mediator diffusion within protein films and thus is dependent on the scaffold morphology. (4) IO-ITO electrodes are superior to IO-graphene as platforms for photoactive bioelectrodes, because their material and structures are more favorable for protein integration and light penetration (Figure 4d). Overall, our study cements the ITO-SA $750 \mathrm{~nm}$ electrode as the benchmark platform for PF-PEC due to the following advantages: (1) the hierarchical electrode architecture provides abundant conductive and hydrophilic mesoporous surfaces to secure proteins within the scaffold; (2) the polydispersed ITO nanoparticles create cavities with dimensions similar to PSII and enable numerous contact sites to interface with the protein; (3) ITO has low light absorbance, thereby allowing high light transmission and internal scattering in the 3D scaffold (Figure 4e).

Further studies are needed to elucidate the mass transport in protein films integrated in 3D electrode scaffolds. The PSII-3D electrode represents a model system in semiartificial photosynthesis, and exemplifies the biotic-abiotic hybrid system that underlies a broad range of applications such as biosensing, biocatalysis, and biofuel production. This study advances our understanding of semiartificial photosynthesis and presents a set of methodologies to probe protein-electrode interactions, which will underpin the ongoing efforts to reproduce the high bioactivity in artificial systems.

\section{ASSOCIATED CONTENT}

\section{Supporting Information}

The Supporting Information is available free of charge on the ACS Publications website at DOI: 10.1021/acs.nanolett.8b04935.

Experimental Section, Supporting Figures S1-S29 and Supporting Tables S1-S3 (PDF)

\section{AUTHOR INFORMATION}

\section{Corresponding Author}

*E-mail: reisner@ch.cam.ac.uk.

ORCID

Tarek A. Kandiel: 0000-0003-0120-2408

Erwin Reisner: 0000-0002-7781-1616

Notes

The authors declare no competing financial interest. Additional data related to this publication are available at the University of Cambridge data repository: https://doi.org/10. 17863/CAM.35772.

\section{ACKNOWLEDGMENTS}

This work was supported by a CSC-Cambridge $\mathrm{PhD}$ scholarship (to X.F.), an EPSRC PhD studentship (to K.P.S.), a Newton-Mosharafa Research Fellowship (to T.K.), the ERC Consolidator Grant "MatEnSAP" (682833 to E.R., N.H., and J.Z.Z). The authors acknowledge Professor A. William Rutherford and Dr. Andrea Fantuzzi from Imperial College London for providing PSII and the following people for their assistance in performing characterizations: Dr. Heather Greer for TEM, Dr. Demetra Achilleos for XRD, Dr. Martin O. Lenz for CLSM, Mr. Daniel Anton Garcia for fluorescence spectroscopy, Dr. Michael Casford for AFM, and Miss Jane Leung for contact angle measurements. The authors also thank Dr. Nikolay Kornienko, Dr. Shafeer Kalathil, and Dr. William Robinson for giving helpful feedback on this work.

\section{REFERENCES}

(1) Barber, J. Chem. Soc. Rev. 2009, 38, 185-196.

(2) Croce, R.; van Amerongen, H. Nat. Chem. Biol. 2014, 10, 492501

(3) Vinyard, D. J.; Ananyev, G. M.; Dismukes, G. C. Annu. Rev. Biochem. 2013, 82, 577-606.

(4) Ferreira, K. N.; Iverson, T. M.; Maghlaoui, K.; Barber, J.; Iwata, S. Science 2004, 303, 1831-1838.

(5) Kato, M.; Zhang, J. Z.; Paul, N.; Reisner, E. Chem. Soc. Rev. 2014, 43, 6485-6497.

(6) Nelson, N.; Ben-Shem, A. Nat. Rev. Mol. Cell Biol. 2004, 5, 971982 .

(7) Brinkert, K.; Le Formal, F.; Li, X.; Durrant, J.; Rutherford, A. W.; Fantuzzi, A. Biochim. Biophys. Acta, Bioenerg. 2016, 1857, 1497-1505.

(8) Zhang, J. Z.; Sokol, K. P.; Paul, N.; Romero, E.; van Grondelle, R.; Reisner, E. Nat. Chem. Biol. 2016, 12, 1046-1052.

(9) Lee, S. H.; Choi, D. S.; Kuk, S. K.; Park, C. B. Angew. Chem., Int Ed. 2018, 57, 7958-7985.

(10) Liu, C.; Gallagher, J. J.; Sakimoto, K. K.; Nichols, E. M.; Chang, C. J.; Chang, M. C. Y.; Yang, P. Nano Lett. 2015, 15, 3634-3639.

(11) Nam, D. H.; Zhang, J. Z.; Andrei, V.; Kornienko, N.; Heidary, N.; Wagner, A.; Nakanishi, K.; Sokol, K. P.; Slater, B.; Zebger, I.; Hofmann, S.; Fontecilla-Camps, J. C.; Park, C. B.; Reisner, E. Angew. Chem., Int. Ed. 2018, 57, 10595-10599.

(12) Badura, A.; Esper, B.; Ataka, K.; Grunwald, C.; Wöll, C.; Kuhlmann, J.; Heberle, J.; Rögner, M. Photochem. Photobiol. 2006, 82, $1385-1390$ 
(13) Li, J.; Feng, X.; Fei, J.; Cai, P.; Huang, J.; Li, J. J. Mater. Chem. A 2016, 4, 12197-12204.

(14) Li, J.; Feng, X.; Jia, Y.; Yang, Y.; Cai, P.; Huang, J.; Li, J. J. Mater. Chem. A 2017, 5, 19826-19835.

(15) Badura, A.; Guschin, D.; Esper, B.; Kothe, T.; Neugebauer, S.; Schuhmann, W.; Rögner, M. Electroanalysis 2008, 20, 1043-1047.

(16) Li, G.; Feng, X.; Fei, J.; Cai, P.; Li, J.; Huang, J.; Li, J. Adv. Mater. Interfaces 2017, 4, 1600619.

(17) Wang, W.; Wang, Z.; Zhu, Q.; Han, G.; Ding, C.; Chen, J.; Shen, J.-R.; Li, C. Chem. Commun. 2015, 51, 16952-16955.

(18) Kothe, T.; Plumeré, N.; Badura, A.; Nowaczyk, M. M.; Guschin, D. A.; Rögner, M.; Schuhmann, W. Angew. Chem., Int. Ed. 2013, 52, 14233-14236.

(19) Yates, N. D. J.; Fascione, M. A.; Parkin, A. Chem. - Eur. J. 2018, 24, 12164-12182.

(20) Saboe, P. O.; Conte, E.; Farell, M.; Bazan, G. C.; Kumar, M. Energy Environ. Sci. 2017, 10, 14-42.

(21) Stieger, K. R.; Feifel, S. C.; Lokstein, H.; Hejazi, M.; Zouni, A.; Lisdat, F. J. Mater. Chem. A 2016, 4, 17009-17017.

(22) Ciornii, D.; Riedel, M.; Stieger, K. R.; Feifel, S. C.; Hejazi, M.; Lokstein, H.; Zouni, A.; Lisdat, F. J. Am. Chem. Soc. 2017, 139, $16478-16481$.

(23) Zhang, J. Z.; Bombelli, P.; Sokol, K. P.; Fantuzzi, A.; Rutherford, A. W.; Howe, C. J.; Reisner, E. J. Am. Chem. Soc. 2018, 140, 6-9.

(24) Sokol, K. P.; Robinson, W. E.; Warnan, J.; Kornienko, N.; Nowaczyk, M. M.; Ruff, A.; Zhang, J. Z.; Reisner, E. Nat. Energy 2018, 3, 944-951.

(25) Mersch, D.; Lee, C.-Y.; Zhang, J. Z.; Brinkert, K.; FontecillaCamps, J. C.; Rutherford, A. W.; Reisner, E. J. Am. Chem. Soc. 2015, 137, 8541-8549.

(26) Sokol, K. P.; Mersch, D.; Hartmann, V.; Zhang, J. Z.; Nowaczyk, M. M.; Rögner, M.; Ruff, A.; Schuhmann, W.; Plumeré, N.; Reisner, E. Energy Environ. Sci. 2016, 9, 3698-3709.

(27) Karimi, A.; Othman, A.; Uzunoglu, A.; Stanciu, L.; Andreescu, S. Nanoscale 2015, 7, 6909-6923.

(28) Wang, Y.; Li, Z.; Wang, J.; Li, J.; Lin, Y. Trends Biotechnol. 2011, 29, 205-212.

(29) Dreyer, D. R.; Park, S.; Bielawski, C. W.; Ruoff, R. S. Chem. Soc. Rev. 2010, 39, 228-240.

(30) Liu, J.; Tang, J.; Gooding, J. J. J. Mater. Chem. 2012, 22, $12435-12452$.

(31) Guo, J.; Zhang, T.; Hu, C.; Fu, L. Nanoscale 2015, 7, 12901295.

(32) Sun, C.; Walker, K. L.; Wakefield, D. L.; Dichtel, W. R. Chem. Mater. 2015, 27, 4499-4504.

(33) Gunther, D.; LeBlanc, G.; Prasai, D.; Zhang, J. R.; Cliffel, D. E.; Bolotin, K. I.; Jennings, G. K. Langmuir 2013, 29, 4177-4180.

(34) Cai, P.; Feng, X.; Fei, J.; Li, G.; Li, J.; Huang, J.; Li, J. Nanoscale 2015, 7, 10908-10911.

(35) Pankratova, G.; Pankratov, D.; Di Bari, C.; Goñi-Urtiaga, A.; Toscano, M. D.; Chi, Q.; Pita, M.; Gorton, L.; De Lacey, A. L. ACS Appl. Energy Mater. 2018, 1, 319-323.

(36) LeBlanc, G.; Winter, K. M.; Crosby, W. B.; Jennings, G. K.; Cliffel, D. E. Adv. Energy Mater. 2014, 4, 1301953.

(37) Darby, E.; LeBlanc, G.; Gizzie, E. A.; Winter, K. M.; Jennings, G. K.; Cliffel, D. E. Langmuir 2014, 30, 8990-8994.

(38) Feifel, S. C.; Lokstein, H.; Hejazi, M.; Zouni, A.; Lisdat, F. Langmuir 2015, 31, 10590-10598.

(39) Wang, H.; Sun, K.; Tao, F.; Stacchiola, D. J.; Hu, Y. H. Angew. Chem., Int. Ed. 2013, 52, 9210-9214.

(40) Qiu, B.; Xing, M.; Zhang, J. Chem. Soc. Rev. 2018, 47, 21652216.

(41) Xue, Y.; Liu, J.; Chen, H.; Wang, R.; Li, D.; Qu, J.; Dai, L. Angew. Chem., Int. Ed. 2012, 51, 12124-12127.

(42) Sasaki, T.; Endo, Y.; Nakaya, M.; Kanie, K.; Nagatomi, A.; Tanoue, K.; Nakamura, R.; Muramatsu, A. J. Mater. Chem. 2010, 20, 8153-8157.
(43) Choi, B. G.; Yang, M.; Hong, W. H.; Choi, J. W.; Huh, Y. S. ACS Nano 2012, 6, 4020-4028.

(44) Wang, X.; Zhi, L.; Müllen, K. Nano Lett. 2008, 8, 323-327.

(45) Bagri, A.; Mattevi, C.; Acik, M.; Chabal, Y. J.; Chhowalla, M.; Shenoy, V. B. Nat. Chem. 2010, 2, 581-587.

(46) Mattevi, C.; Eda, G.; Agnoli, S.; Miller, S.; Mkhoyan, K. A.; Celik, O.; Mastrogiovanni, D.; Granozzi, G.; Garfunkel, E.; Chhowalla, M. Adv. Funct. Mater. 2009, 19, 2577-2583.

(47) Park, S.; Ruoff, R. S. Nat. Nanotechnol. 2009, 4, 217-224.

(48) Mulyana, Y.; Uenuma, M.; Ishikawa, Y.; Uraoka, Y. J. Phys. Chem. C 2014, 118, 27372-27381.

(49) Simon, P.; Gogotsi, Y. Nat. Mater. 2008, 7, 845-854.

(50) Kim, H.; Gilmore, C. M.; Piqué, A.; Horwitz, J. S.; Mattoussi, H.; Murata, H.; Kafafi, Z. H.; Chrisey, D. B. J. Appl. Phys. 1999, 86, 6451-6461.

(51) Mierzwa, M.; Lamouroux, E.; Walcarius, A.; Etienne, M. Electroanalysis 2018, 30, 1241-1258.

(52) Neale, N. R.; Lee, B. G.; Kang, S. H.; Frank, A. J. J. Phys. Chem. C 2011, 115, 14341-14346.

(53) Chen, J. I. L.; von Freymann, G.; Kitaev, V.; Ozin, G. A. J. Am. Chem. Soc. 2007, 129, 1196-1202.

(54) Liao, G.; Chen, S.; Quan, X.; Yu, H.; Zhao, H. J. Mater. Chem. 2012, 22, 2721-2726.

(55) Glassford, S. E.; Byrne, B.; Kazarian, S. G. Biochim. Biophys. Acta, Proteins Proteomics 2013, 1834, 2849-2858.

(56) Reuillard, B.; Ly, K. H.; Rosser, T. E.; Kuehnel, M. F.; Zebger, I.; Reisner, E. J. Am. Chem. Soc. 2017, 139, 14425-14435.

(57) Berthomieu, C.; Hienerwadel, R. Biochim. Biophys. Acta, Bioenerg. 2005, 1707, 51-66.

(58) Hanske, J.; Toffey, J. R.; Morenz, A. M.; Bonilla, A. J.; Schiavoni, K. H.; Pletneva, E. V. Proc. Natl. Acad. Sci. U. S. A. 2012, 109, 125-130.

(59) Goebbert, C.; Nonninger, R.; Aegerter, M. A.; Schmidt, H. Thin Solid Films 1999, 351, 79-84.

(60) Larom, S.; Salama, F.; Schuster, G.; Adir, N. Proc. Natl. Acad. Sci. U. S. A. 2010, 107, 9650-9655.

(61) Khan, S.; Sun, J. S.; Brudvig, G. W. J. Phys. Chem. B 2015, 119, $7722-7728$.

(62) Kato, M.; Cardona, T.; Rutherford, A. W.; Reisner, E. J. Am. Chem. Soc. 2013, 135, 10610-10613.

(63) Lemieux, S.; Carpentier, R. J. Photochem. Photobiol., B 1988, 2, 221-231.

(64) Bukhov, N. G.; Sridharan, G.; Egorova, E. A.; Carpentier, R. Biochim. Biophys. Acta, Bioenerg. 2003, 1604, 115-123. 